\title{
High admission rates and heavy inpatient service costs of urban tuberculosis patients in eastern China
}

\author{
Yang Zhou', Cheng Chen ${ }^{1}$, Hui Jiang ${ }^{2}$, Hong-Qiu Pan ${ }^{3}$, Li-Mei Zhu and Wei Lu ${ }^{1 *}$ (D)
}

\begin{abstract}
Background: Tuberculosis patients often experience hospitalization. Inpatient services may result in high medical expenditures. It is important to explore the hospitalization rates of tuberculosis patients and the potential factors that are associated with admission rates and inpatient service expenditures.

Methods: Data from patients diagnosed and treated at the No.3 hospital of Zhenjiang City from Apr. 2014 to Mar. 2015 were obtained. Univariate and multivariate statistical analyses were applied for the analysis of potential factors associated with admission rates, average length of stay and cost.

Results: A total of 356 tuberculosis patients were treated at the No.3 hospital of Zhenjiang City. A total of 221 of the 356 patients were hospitalized. Sputum smear test results and type of health insurance were the potential factors associated with hospitalization rates. The average admission was (1.26 \pm 0.64$)$ per patient. The average length of stay of inpatients was $29.99 \pm 25.83$ days. Age, occupation, and sputum smear test were related to the average length of stay. The average total cost to inpatients was $13007.91 \pm 5205.58$ CNY. The sputum smear test results, type of health insurance, occupation and age were the main potential factors associated with TB inpatient expenditures.

Conclusions: The admission rate of tuberculosis patients was high. Despite advances in TB insurance policies, there were substantial costs associated with TB diagnosis and treatment. TB patients still face a heavy financial burden. Health care providers should revise the service package and reform the health insurance regulations to ensure that TB patients receive appropriate care.
\end{abstract}

Keywords: Tuberculosis, Inpatient, Financial burden, China

\section{Background}

China is one of the "high burden countries" of tuberculosis (TB), there were 889,000 new TB cases in 2017 according to the estimates of the World Health Organization (WHO). China has the second highest TB epidemic rate in the world [1].

TB remains a serious public health issue and social problem in many developing nations [2]. The Chinese government attaches much importance to TB control. Since the 1990s, the Chinese government has implemented the National Tuberculosis Control Program

\footnotetext{
* Correspondence: weiluxx@yeah.net

${ }^{1}$ Department of Chronic Disease Control and Prevention, Centers for Disease Control and Prevention of Jiangsu Province, 172 Jiangsu Road, Nanjing 210009, Jiangsu Province, People's Republic of China

Full list of author information is available at the end of the article
}

(NTP), the DOTS strategy, free TB diagnosis and treatment, and DOTS-plus to constantly enhance TB control measures [3].

TB has been regarded as a "poverty-related disease" due to its association with poverty and malnutrition [4]. Poverty can decrease the rate of treatment success [5], and TB will also aggravate poverty. In China, suspected tuberculosis patients are provided free diagnosis and antituberculosis treatment, including free chest X-ray examinations, sputum smear tests and designated first-line anti-tuberculosis drugs. However, some patients still cannot afford the share of medical and non-medical costs [6].

Recently, tuberculosis management models have been changing in China. The diagnosis and treatment of $\mathrm{TB}$ patients have been transferred from the Centers for

(c) The Author(s). 2019 Open Access This article is distributed under the terms of the Creative Commons Attribution 4.0 International License (http://creativecommons.org/licenses/by/4.0/), which permits unrestricted use, distribution, and 
Disease Control and Prevention (CDC) to "designated hospitals". Each county has one designated hospital for TB treatment. The designated hospital is usually a public hospital in the county, and most of them are the largest healthcare provider in the county [7]. In China, patients are more likely to seek medical service in the public hospital, including suspected and confirmed TB patients. The 2000 national TB survey reported that 91\% of TB patients visited public hospitals first to treat TB related symptoms [8]. Additionally, TB patients receive better diagnosis and treatment in the designated hospitals, and can also increase adherence to anti-tuberculosis treatment. However, the designated hospital model also has its own disadvantages; patients may not receive the free diagnosis and anti-tuberculosis treatment or they may experience over-examination and a high rate of hospitalization due to poor hospital staff training for TB technical specifications and the economic incentive of the designated hospital. Research from Dr. Li [9] revealed that the rate of hospitalization increased significantly from 62.3 to $98.0 \%$, and the ALOS increased 2 to 4 days after the diagnosis and treatment of TB patients transferred to the designated hospitals. These resulted in a greater financial burden on patients and reduced the likelihood of treatment adherence. Some patients default because of the high financial burden of TB [10].

In 2013, China launched a collaboration with the Bill and Melinda Gates Foundation TB Programme. Under this programme, three project sites, including Zhenjiang City Jiangsu Province, implemented a new policy to standardize TB diagnosis and treatment at the designated hospital and improve reimbursement rates for TB patients. In this paper, we evaluated the effectiveness of the programme. We analysed the admission rates and economic burden of TB patients in Zhenjiang City, and we also explored the potential factors that are associated with high admission rates and inpatient service costs.

\section{Methods}

Study design

In 2004, we began to explore the designated hospital management model in Jiangsu Province, and until 2012, all province counties implemented the designated hospital model. Since 2009, the Bill and Melinda Gates Foundation, in collaboration with the China National Health and Family Planning Commission/China CDC, has been implementing an innovative programme for TB control and prevention in four Chinese cities [11]. In 2013, the second phase of this programme was initiated. Zhenjiang City is one of the three project cities. The programme aims to establish comprehensive TB control models that can standardize clinical behaviour, decrease the rate of hospitalization and increase the reimbursement rate on TB patients.
The targets of the programme are as follows: i) maintain the rate of hospitalization under $30 \%$ and ii) implement case-based payments and develop a standard service package for inpatients. The service package is developed according to examination procedures, including sputum tests, sputum cultures, drug susceptibility tests, chest $\mathrm{X}$-rays, physical examinations, biochemical examinations, and electrocardiogram examinations, and treatment for TB patients, including adverse reaction treatments, ward services, etc. The total cost of the service package was capped at $8000 \mathrm{CNY}$ (Chinese Yuan). For services in the package, patient payment capped at a maximum of $20 \%$ of charges or $1600 \mathrm{CNY}$, and health insurance covered $80 \%$ of charges. Patients whose health insurance covered over $80 \%$ of the package followed the original payment policy. The assessment of the project was conducted in 2015. In this study, we analysed the admission rate and inpatient cost of No. 3 hospital of Zhenjiang City (the designated hospital of Zhenjiang City).

Jiangsu Province lies in eastern China, adjacent to Shanghai City. There are 13 cities in Jiangsu Province. In 2015, the population was 79.76 million and the gross domestic product (GDP) was 70116 billion CNY, GDP per capita was 88085 CNY (14143USD). Zhenjiang City lies in the southeast of Jiangsu Province. In 2015, the population was 3.16 million and the GDP was 3502 billion CNY. GDP per capita was 110440 CNY (17732 USD), ranked fifth in Jiangsu Province.

\section{Data collection}

\section{Medical records from TB designated hospitals}

Active TB patients who lived in Jingkou District, Runzhou District, Dantu District, or Xin District that were diagnosed and treated in the No.3 hospital of Zhenjiang City from Apr. 2014 to Mar. 2015 were all participants, including new patients and retreatment patients. MDR-TB, rifampicin-resistant TB, extrapulmonary $\mathrm{TB}$, and tuberculous pleurisy patients were excluded. Data were obtained from the China TB Management Information System (TMIS), inpatient records were obtained from the Hospital Information System (HIS), expenditures of inpatient cases obtained from Hospital Reimbursement System (HRS). All subjects gave their informed consent for inclusion before they participated in the study.

\section{Expenditure associated with TB treatment}

Fees for services covered by the free-TB service policy were directly deducted and not recorded in the patients' medical records. The total costs were medical inpatient expenses related to $\mathrm{TB}$ diagnosis and treatment. The out-of-pocket (OOP) costs were the total costs calculated by excluding reimbursement through medical insurance. Inpatients who were hospitalized 
for diseases other than tuberculosis were not counted, the medical expenses incurred by the subjects not related to tuberculosis during hospitalization were also not included in the expenses. The costs are expressed in the Chinese Yuan (CNY). In 2015, 1 CNY was equal to 0.16 USD.

\section{Admission indicators}

All of the subjects in this study were TB patients, and the primary diagnosis for hospital admission was TB. Hospital admission was also assessed according to the following indicators: i) Patients with severe complications; ii) Patients with serious adverse reactions requiring further hospitalization; iii) Patients requiring surgery; and iv) Patients with other conditions requiring admission to the hospital as determined by physicians.

\section{Statistical analysis}

Univariate and multivariate analyses were applied to analyse the data. Patient' names were used as a key variable to link the data from TMIS, HIS and the Hospital Reimbursement System. Chi-square tests were used to identify factors associated with admission rates. ANOVA was used to find differences in hospitalization times and the average length of stay (ALOS). Costs were presented as the means (standard deviation, SD) and medians (percentile 25 and percentile 75, p25 and p75) to allow for the expected positively skewed distributions. The Mann-Whitney U and Kruskal-Wallis $\mathrm{H}$ tests were used to compare the cost differences. A binary logistic regression was used to explore the association between the characteristics of TB patients and the occurrence of hospitalization, and a generalized linear regression was used to explore the association between the characteristics and the medical cost for TB inpatient care. Statistical significance was set at $5 \%$. The statistical package SPSS 20.0(Texas, USA) was used to analyse the data.

\section{Results}

\section{Demographic and social characteristics}

Three hundred fifty-six TB patients (Additional file 1) were diagnosed and treated at the No.3 hospital of Zhenjiang City from Apr. 2014 to Mar. 2015. Table 1 shows that approximately $75.8 \%$ of patients were men, and $24.2 \%$ of patients were women. A large majority were aged 45 years and older (66.8\%). Among the 356 patients, $43.2 \%$ were manual labourers. A large majority were new cases, and only $14.6 \%$ were previously treated cases. More than half of the TB patients were native to Zhenjiang City, and $46.9 \%$ of the patients were smear-positive cases.
Table 1 Demographic and social characteristics of the 356 TB patients (N/\%)

\begin{tabular}{|c|c|c|}
\hline Variables & $n$ & $\%$ \\
\hline \multicolumn{3}{|l|}{ Gender } \\
\hline Male & 270 & 75.8 \\
\hline Female & 86 & 24.2 \\
\hline \multicolumn{3}{|l|}{ Age } \\
\hline$<30$ & 70 & 19.7 \\
\hline $30 \sim 44$ & 48 & 13.5 \\
\hline $45 \sim 59$ & 99 & 27.8 \\
\hline $60 \sim$ & 139 & 39.0 \\
\hline \multicolumn{3}{|l|}{ Occupation } \\
\hline Mental labourer ${ }^{\mathrm{a}}$ & 34 & 9.6 \\
\hline Manual labourer ${ }^{\mathrm{b}}$ & 154 & 43.2 \\
\hline Retire $^{c}$ & 146 & 41.0 \\
\hline Unknown & 22 & 6.2 \\
\hline \multicolumn{3}{|l|}{ Patient category } \\
\hline New cases & 304 & 85.4 \\
\hline Previously treated cases & 52 & 14.6 \\
\hline \multicolumn{3}{|l|}{ Residence } \\
\hline Native & 203 & 57.0 \\
\hline Migration in China & 153 & 43.0 \\
\hline Sputum smear test & & 0.0 \\
\hline Negative cases & 189 & 53.1 \\
\hline Positive cases & 167 & 46.9 \\
\hline
\end{tabular}

${ }^{a}$ Mental labourer, including students, teachers, health workers and governmental personnel

${ }^{\mathrm{b}}$ Manual labourer, including farmers, rural migrant workers, shepherd 'Retire including retire and housekeeping

\section{Admission rate and potential factors associated with the admission rate Admission rate}

Patient' names were used as key variables to link the data from TMIS and HIS. We found that 221 patients among the 356 patients were hospitalized (Additional file 2). According to Table 2, most of the inpatients were male $(P$ $=0.017$ ). There were significant differences in the hospitalization rates between smear-positive and smear-negative patients $(P<0.001)$. The hospitalization rate of patients covered by student health insurance was significantly higher than that of patients covered by the Urban Resident Basic Medical Insurance scheme (URBMI) and the Urban Employee Basic Medical Insurance scheme (UEBMI) or without insurance.

\section{The potential factors associated with admission rates}

A binary logistic regression was used to explore the association between six characteristics of TB patients (gender, age, occupation, patient category, residence, sputum smear test and health insurance) and the 
Table 2 Analysis on hospitalization rates of 356 TB patients

\begin{tabular}{|c|c|c|c|c|c|}
\hline Variables & Total patients & Inpatients & Hospitalization rate (\%) & Chi-Square & $P$-value \\
\hline \multicolumn{6}{|l|}{ Gender } \\
\hline Male & 270 & 177 & 65.6 & \multirow[t]{2}{*}{5.740} & \multirow[t]{2}{*}{0.017} \\
\hline Female & 86 & 44 & 51.2 & & \\
\hline \multicolumn{6}{|l|}{ Age } \\
\hline$<30$ & 70 & 40 & 57.1 & \multirow[t]{4}{*}{4.444} & \multirow[t]{4}{*}{0.217} \\
\hline $30 \sim 44$ & 48 & 26 & 54.2 & & \\
\hline $45 \sim 59$ & 99 & 69 & 69.7 & & \\
\hline $60 \sim$ & 139 & 86 & 61.9 & & \\
\hline \multicolumn{6}{|l|}{ Occupation } \\
\hline Mental labourer & 34 & 22 & 64.7 & \multirow[t]{4}{*}{2.691} & \multirow[t]{4}{*}{0.442} \\
\hline Manual labourer & 154 & 89 & 57.8 & & \\
\hline Retire & 146 & 94 & 64.4 & & \\
\hline Unknown & 22 & 16 & 72.7 & & \\
\hline \multicolumn{6}{|l|}{ Patient category } \\
\hline New cases & 304 & 183 & 60.2 & \multirow[t]{2}{*}{3.129} & \multirow[t]{2}{*}{0.077} \\
\hline Previously treated cases & 52 & 38 & 73.1 & & \\
\hline \multicolumn{6}{|l|}{ Residence } \\
\hline Native & 203 & 130 & 64.0 & \multirow[t]{2}{*}{0.771} & \multirow[t]{2}{*}{0.380} \\
\hline Migration in China & 153 & 91 & 59.5 & & \\
\hline \multicolumn{6}{|l|}{ Sputum smear test } \\
\hline Negative cases & 189 & 92 & 48.7 & \multirow[t]{2}{*}{30.738} & \multirow[t]{2}{*}{0.000} \\
\hline Positive cases & 167 & 129 & 77.2 & & \\
\hline \multicolumn{6}{|l|}{ Health Insurance } \\
\hline URBMI & 136 & 80 & 58.8 & \multirow[t]{4}{*}{7.893} & \multirow[t]{4}{*}{0.048} \\
\hline UEBMI & 161 & 96 & 59.6 & & \\
\hline Student & 13 & 12 & 92.3 & & \\
\hline Without insurance & 46 & 33 & 71.7 & & \\
\hline
\end{tabular}

occurrence of hospitalization by computing odds ratios (ORs). Table 3 shows that sputum-smear positive patients were more likely to have higher hospitalization rates than sputum smear-negative patients $(\mathrm{OR}=3.576$, $P=0.000$ ). Significant differences were found in the hospitalization rates in health insurance. TB patients covered by student insurance and patients without insurance were more likely to be hospitalized.

In Table 4, 221 inpatients experienced 279 hospitalizations with an average of $1.26 \pm 0.64$ admissions per patient. A total of $19.9 \%$ of inpatients were hospitalized at least once. The ALOS of inpatients was 29.99 \pm 25.83 days, and $34.4 \%$ of inpatients were hospitalized over 4 weeks. There was a significant difference in the hospitalization times associated with the type of health insurance $(P=0.005)$. A univariate analysis identified several features related to ALOS, including age, occupation, and sputum smear status. The ALOS of positive cases was longer than that of negative cases.

\section{Inpatient economic burden and the potential factors associated with medical expenditure Inpatients' economic burden}

We obtained medical expenditure records for 141 of the 221inpatients (Additional file 3). As shown in Table 5, the average (median, IQR) total costs of service package was 7219.78(7503.03, 6251.10-7942.20) CNY, and the OOP costs were 1320.24 (1433.13, 1179.55-1570.76) CNY. The median (IQR) ratio of OOP costs to total costs was 20.00\% (19.15-20.00). Except for the costs of the service package, patients still had to pay a substantial proportion medical expenditures occurred out of the service package, which was almost half of the total costs. The median (IQR) ratio of OOP costs to total costs out of the service package was $41.88 \%$ (26.23-55.57). The average (median, 
Table 3 Multivariate analysis of the potential factors influence hospitalization rates of the 356 TB patients

\begin{tabular}{|c|c|c|c|c|c|}
\hline Independent variables & $\beta$ & SE & $P$-value & OR & $95 \% \mathrm{Cl}$ \\
\hline Gender (Compare with female) & 0.412 & 0.277 & 0.137 & 1.510 & $0.877-2.599$ \\
\hline Age (Compare with <30) & & & 0.167 & 1.000 & \\
\hline Age $30-44$ & 0.038 & 0.440 & 0.931 & 1.039 & $0.438-2.460$ \\
\hline Age $45-59$ & 0.757 & 0.394 & 0.054 & 2.132 & $0.986-4.611$ \\
\hline Age $60+$ & 0.380 & 0.383 & 0.322 & 1.462 & $0.689-3.099$ \\
\hline Occupation (Compare with Mental labourer) & & & 0.304 & 1.000 & \\
\hline Manual labourer & 0.352 & 0.533 & 0.509 & 1.422 & $0.501-4.037$ \\
\hline Retire & 0.707 & 0.542 & 0.192 & 2.027 & $0.701-5.864$ \\
\hline Unknown & 1.018 & 0.718 & 0.156 & 2.768 & $0.678-11.297$ \\
\hline Patient category (Compare with new patients) & -0.043 & 0.380 & 0.909 & 0.958 & $0.455-2.015$ \\
\hline Residence (Compare with native) & -0.038 & 0.249 & 0.878 & 0.962 & $0.591-1.567$ \\
\hline Sputum smear test (Compare with Negative) & 1.274 & 0.261 & 0.000 & 3.576 & $2.143-5.968$ \\
\hline Health insurance (Compare with UEBMI) & & & 0.012 & 1.000 & \\
\hline URBMI & 0.147 & 0.280 & 0.598 & 1.159 & $0.670-2.005$ \\
\hline Student & 3.397 & 1.177 & 0.004 & 29.865 & $2.976-1299.701$ \\
\hline Without insurance & 0.834 & 0.415 & 0.045 & 2.302 & $1.021-5.192$ \\
\hline
\end{tabular}

IQR) total cost to inpatients was 13007.91(11674.20, 10054.08-15579.08) CNY.

\section{The potential factors associated with the high expenditure of inpatients}

In Table 6, the expenditures of native patients were higher than the costs of migration in China $(P=0.035)$ in the service package. Out of the service package, a univariate analysis showed several features related to OOP expenditures, including occupation and type of health insurance. There was a different reimbursement rate outlined by the reimbursement policy. The expenditure for manual labourers, which was always farmers, was higher than in other occupations, and the reimbursement rate was usually lower than in other populations. The total OOP situation was the same.

We also tried to find associations between the characteristics of TB patients and medical expenditures. Generalized linear regression analysis was used, in which the $\log$ of the medical expenditures was the dependent variable as the data were skewed. Table 7 indicates that total costs were positively correlated with occupation and sputum smear-positive patients. The expenditure of smearpositive patients $(12384.00 \mathrm{CNY})$ was higher than that of smear-negative patients (11260.25 CNY). The results also revealed that type of health insurance, occupation and age were potentially associated with total OOP costs. The expenditure for manual labourers was much higher than that of other occupations. Another factor that could have influenced the OOP expenditure of inpatient services was type of health insurance. Patients covered by URBMI (3736.14 CNY) paid more than patients covered by
UEBMI (2910.21 CNY) and student insurance (2670.59 CNY), because out of the service package, the reimbursement rate of URBMI was lower than that of UEBMI and student insurance.

\section{Discussion}

This study explored the admission rate of TB patients and analysed the expenditures of inpatients in Zhenjiang City. The results revealed that the admission rate of TB patients was high. TB inpatients had to bear a heavy economic burden, even with the free TB policy in China. With this policy, sputum smear tests, free chest X-ray examinations and first-line anti-tuberculosis drugs are provided to TB patients [12-14]. The study also revealed that the sputum smear test results, type of health insurance, occupation and age were the main potential factors associated with TB patient admission rate and inpatient expenditures.

Outpatient treatment is recommended by the WHO for non-complicated tuberculosis patients [15]. In this study, the admission rate of $\mathrm{TB}$ patients was $62.1 \%$, which exceeded the target of the programme and higher than in the previous study [16]. In this article, a binary logistic regression analysis showed that sputum smear-positive patients and students were more likely to have higher hospitalization rates. First, sputum smearpositive patients often were seriously ill or accompanied by complications, and patients were more likely to be hospitalized. Second, with the decrease in government funding for public hospitals in China, insurance and patient payments are the main sources of income for health facilities [17]. Physicians employed by hospitals are rewarded 
Table 4 Factors related to the average times of hospitalization and ALOS of the 221 inpatients

\begin{tabular}{|c|c|c|c|c|c|c|c|}
\hline$\underline{\text { Variables }}$ & Inpatients & Times of hospitalization & $F^{a}$ & $P$-value & ALOS & $F^{a}$ & $P$-value \\
\hline \multicolumn{8}{|l|}{ Gender } \\
\hline Male & 177 & $1.25 \pm 0.60$ & 0.148 & 0.701 & $30.72 \pm 27.08$ & 0.880 & 0.349 \\
\hline Female & 44 & $1.30 \pm 0.76$ & & & $27.12 \pm 20.17$ & & \\
\hline \multicolumn{8}{|l|}{ Age } \\
\hline$<30$ & 40 & $1.18 \pm 0.45$ & 0.459 & 0.711 & $33.68 \pm 23.17$ & 4.464 & 0.004 \\
\hline $30 \sim 44$ & 26 & $1.23 \pm 0.43$ & & & $35.72 \pm 24.24$ & & \\
\hline $45 \sim 59$ & 69 & $1.26 \pm 0.50$ & & & $34.59 \pm 34.87$ & & \\
\hline $60 \sim$ & 86 & $1.31 \pm 0.83$ & & & $23.28 \pm 16.19$ & & \\
\hline \multicolumn{8}{|l|}{ Occupation } \\
\hline Mental labourer & 22 & $1.45 \pm 1.14$ & 1.097 & 0.351 & $29.81 \pm 26.59$ & 3.639 & 0.013 \\
\hline Manual labourer & 89 & $1.19 \pm 0.45$ & & & $27.68 \pm 16.58$ & & \\
\hline Retire & 94 & $1.29 \pm 0.65$ & & & $29.09 \pm 28.44$ & & \\
\hline Unknown & 16 & $1.25 \pm 0.45$ & & & $47.90 \pm 40.06$ & & \\
\hline \multicolumn{8}{|l|}{ Patient category } \\
\hline New cases & 183 & $1.24 \pm 0.64$ & 1.279 & 0.259 & $28.98 \pm 23.64$ & 1.860 & 0.174 \\
\hline Previously treated cases & 38 & $1.37 \pm 0.63$ & & & $34.38 \pm 33.68$ & & \\
\hline \multicolumn{8}{|l|}{ Residence } \\
\hline Native & 130 & $1.32 \pm 0.74$ & 2.901 & 0.090 & $29.69 \pm 22.71$ & 0.058 & 0.810 \\
\hline Migration in China & 91 & $1.18 \pm 0.44$ & & & $30.46 \pm 30.28$ & & \\
\hline \multicolumn{8}{|l|}{ Sputum smear test } \\
\hline Negative cases & 92 & $1.22 \pm 0.59$ & 0.792 & 0.374 & $22.76 \pm 11.55$ & 15.409 & 0.000 \\
\hline Positive cases & 129 & $1.29 \pm 0.67$ & & & $34.83 \pm 31.13$ & & \\
\hline \multicolumn{8}{|l|}{ Health Insurance } \\
\hline URBMI & 80 & $1.14 \pm 0.38$ & 4.465 & 0.005 & $30.95 \pm 32.05$ & 1.529 & 0.207 \\
\hline UEBMI & 96 & $1.42 \pm 0.83$ & & & $27.74 \pm 21.08$ & & \\
\hline Student & 12 & $1.42 \pm 0.67$ & & & $26.88 \pm 18.32$ & & \\
\hline Without insurance & 33 & $1.06 \pm 0.24$ & & & $37.74 \pm 26.89$ & & \\
\hline
\end{tabular}

${ }^{a}$ ANOVA test

Table 5 Medical expenditure of 141 inpatients

\begin{tabular}{|c|c|c|c|c|c|}
\hline Costs & mean & SD & median & $25 \%$ & $75 \%$ \\
\hline \multicolumn{6}{|c|}{ Service package } \\
\hline Total & 7219.78 & 1900.81 & 7503.03 & 6251.10 & 7942.20 \\
\hline OOP & 1320.24 & 332.88 & 1433.13 & 1179.55 & 1570.76 \\
\hline OOP/Total & 18.58 & 3.30 & 20.00 & 19.15 & 20.00 \\
\hline \multicolumn{6}{|l|}{ Out of service } \\
\hline Total & 5788.13 & 4814.67 & 4127.52 & 2865.05 & 7633.46 \\
\hline OOP & 2198.35 & 1760.18 & 1738.12 & 870.68 & 2836.55 \\
\hline OOP/Total & 40.02 & 16.64 & 41.88 & 26.23 & 55.57 \\
\hline \multicolumn{6}{|l|}{ Total costs } \\
\hline Total & $13,007.91$ & 5205.58 & $11,674.20$ & $10,054.08$ & $15,579.08$ \\
\hline $\mathrm{OOP}$ & 3518.60 & 1868.56 & 3125.85 & 2203.58 & 4222.57 \\
\hline OOP/Total & 26.89 & 8.65 & 27.10 & 20.41 & 33.22 \\
\hline
\end{tabular}

with bonuses and promotions based on the profits they generate by admitting patients, recommending diagnostic tests, and prescribing medications. This undoubtedly encourages physicians to increase the hospitalization of $\mathrm{TB}$ patients. Third, considering that tuberculosis is an infectious disease, parents and school administrators worried about the spread of TB infection within the family and in the school. Therefore, they prefer the students to be admitted to the hospital. Patients without insurance also had a high hospitalization rate. The target hospitalization rate of less than 30\% was restricted to patients with insurance. Patients without insurance were not controlled by the health department.

In this study, we found that the ALOS of positive TB patients was $34.83 \pm 31.13$ days, which was longer than the ALOS of negative TB patients ( $22.76 \pm 11.55$ days). Previous studies have shown that smear-positive TB patients admitted to hospitals after 14 days of anti- 


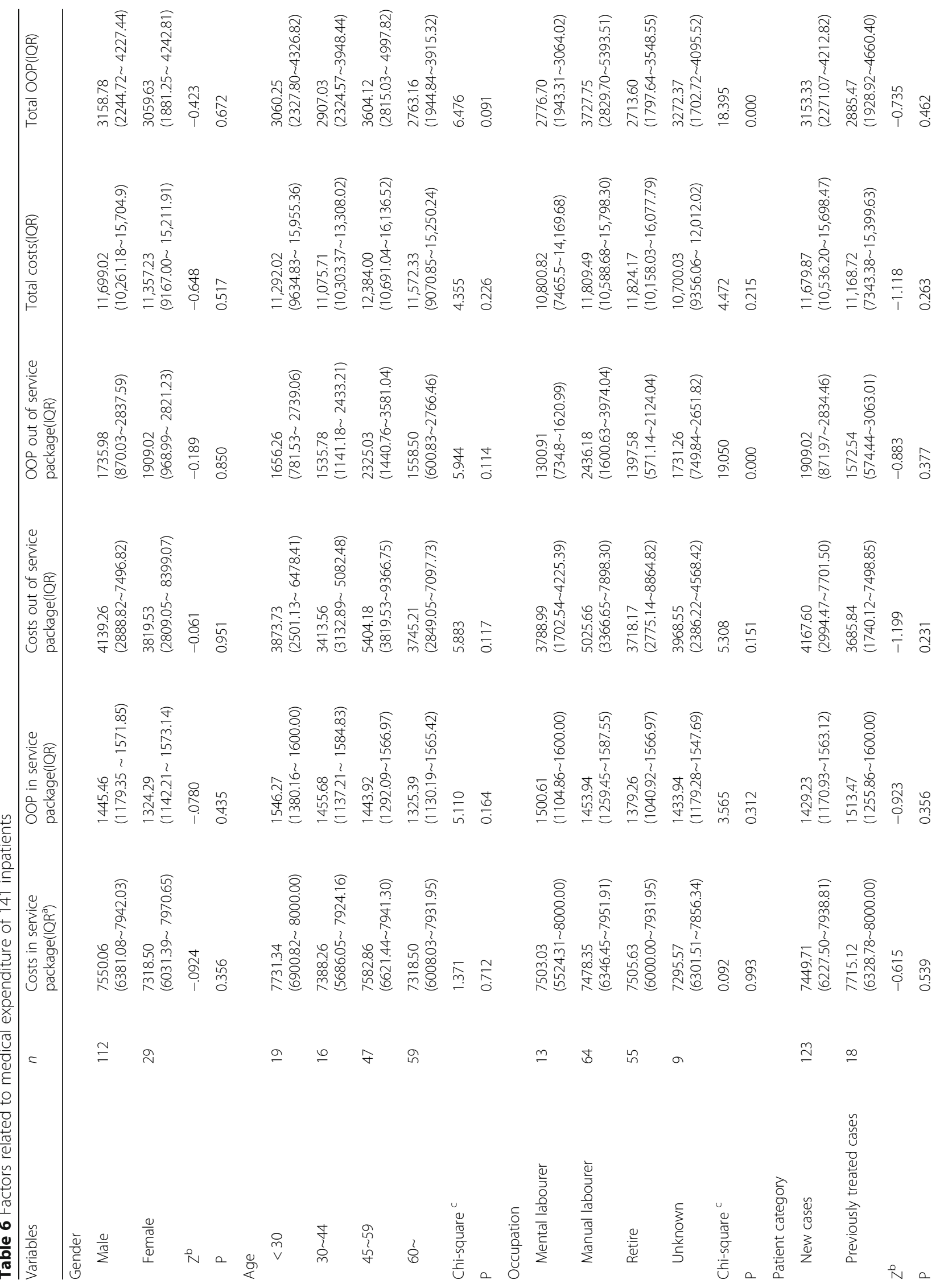




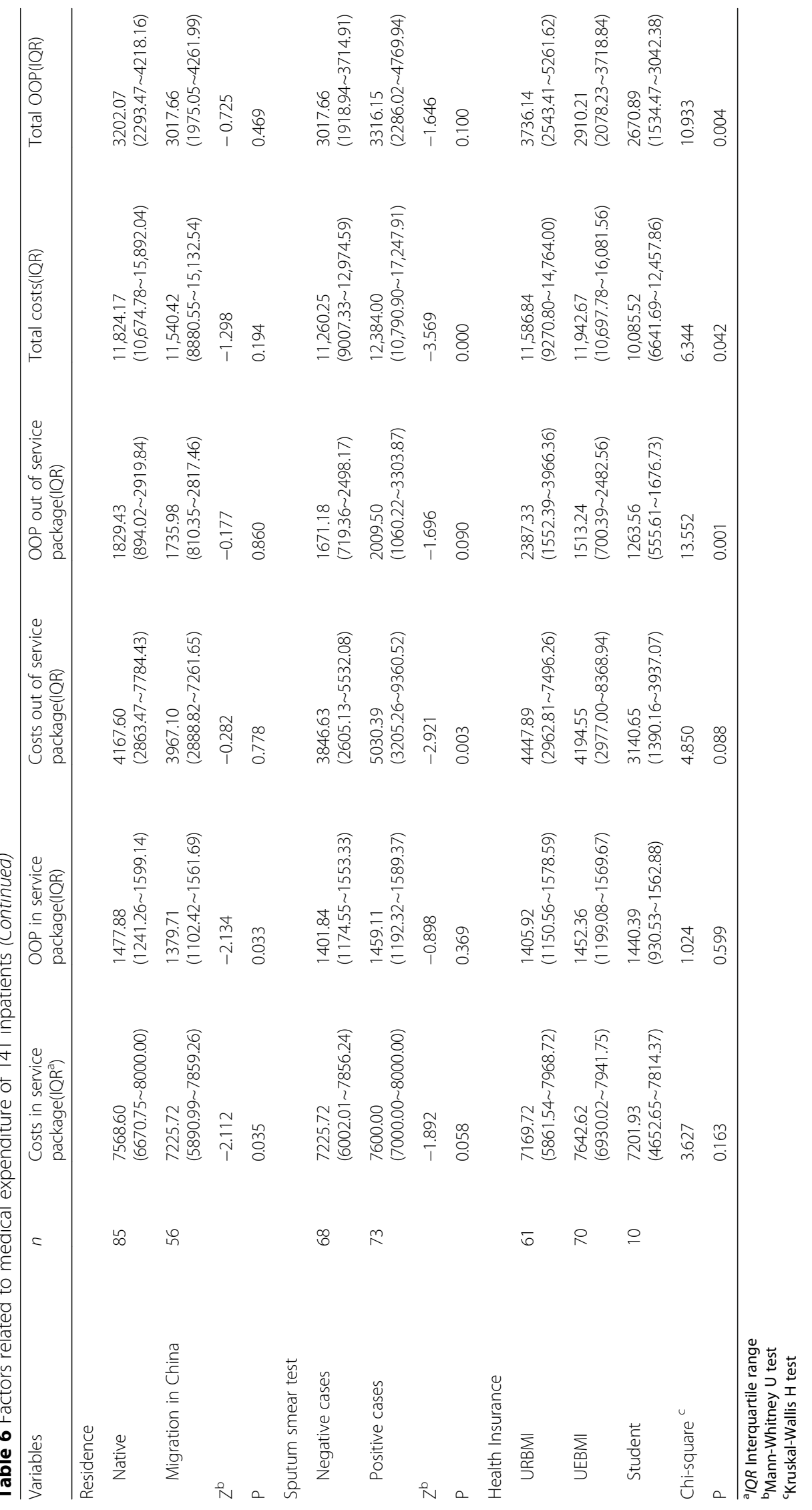


Table 7 Generalized linear regression analysis of potential factors influence medical costs

\begin{tabular}{|c|c|c|c|c|c|c|}
\hline \multirow[t]{2}{*}{ Variables } & \multicolumn{3}{|c|}{ Total costs } & \multicolumn{3}{|c|}{ Total OOP costs } \\
\hline & $\bar{\beta}$ & SE & $P$-value & $\bar{\beta}$ & SE & $P$-value \\
\hline Intercept & 8.944 & 0.286 & 0.000 & 7.359 & 0.411 & 0.000 \\
\hline UEBMI & 0.398 & 0.238 & 0.094 & 0.771 & 0.341 & 0.024 \\
\hline URBMI & 0.350 & 0.241 & 0.146 & 0.924 & 0.347 & 0.008 \\
\hline Student & $0^{\mathrm{a}}$ & & & $0^{\mathrm{a}}$ & & \\
\hline Male & 0.003 & 0.072 & 0.972 & -0.041 & 0.103 & 0.691 \\
\hline Female & $0^{a}$ & & & $0^{\mathrm{a}}$ & & \\
\hline Mental labourer & 0.281 & 0.229 & 0.220 & 0.473 & 0.330 & 0.151 \\
\hline Manual labourer & 0.247 & 0.125 & 0.048 & 0.390 & 0.180 & 0.030 \\
\hline Retire & 0.219 & 0.125 & 0.079 & 0.069 & 0.180 & 0.699 \\
\hline Unknown & $0^{a}$ & & & $0^{\mathrm{a}}$ & & \\
\hline New cases & 0.164 & 0.091 & 0.069 & 0.138 & 0.130 & 0.288 \\
\hline Previously treated cases & $0^{a}$ & & & $0^{\mathrm{a}}$ & & \\
\hline Native & 0.038 & 0.061 & 0.531 & 0.064 & 0.088 & 0.468 \\
\hline Migration in China & $0^{a}$ & & & $0^{\mathrm{a}}$ & & \\
\hline Negative cases & -0.200 & 0.061 & 0.001 & -0.064 & 0.088 & 0.465 \\
\hline Positive cases & $0^{a}$ & & & $0^{\mathrm{a}}$ & & \\
\hline Age & -0.003 & 0.002 & 0.107 & -0.008 & 0.003 & 0.005 \\
\hline Scale & $0.111^{\mathrm{b}}$ & 0.013 & & $0.229^{b}$ & 0.027 & \\
\hline
\end{tabular}

Dependent variable:total costs/total OOP costs

Model (intercept): health insurance, gender, occupation, patient category, residence, sputum smear test and age

a Set to zero because this parameter is redundant

b Maximum likelihood estimate

tuberculosis treatment had a sputum negative conversion rate of $61.15 \%$; there still had $38.85 \%$ of patients had sputum smear-positive results [18]. Considering infection control, doctors tend to extend the length of hospital stay for smear-positive patients [19, 20].

Physicians should restrict hospitalization and shorten the length of stay according to the admission indicators. Outpatient treatment not only deceases the economic burden but also avoids nosocomial infections and the spread of MDR-TB. However, unnecessary hospitalization has been reported and leads to higher inpatient expenses [21]. Hospitalization may be responsible for the high financial burden on TB patients [12, 22, 23]. The medical expenditure of inpatients was 3.28 times that of outpatients [24]. In 2007, a study showed that ALOS was 28.8 days, and the average cost of inpatients was 7725.6 CNY [25]. In our study, the ALOS was 29.99 days, $34.4 \%$ of inpatients were hospitalized over 4 weeks. Long hospital stays and unnecessary examinations have caused a heavy burden of TB [26].

There are three basic health insurance schemes in China. UEBMI, a compulsory scheme, was established for the urban residents who formally work. URBMI, a voluntary scheme, was established for the rest of urban residents without formal jobs or who are unemployed, such as children, elderly, and the unemployed young.
The New Rural Cooperative Medical Scheme (NCMS), a voluntary scheme, was established for rural areas. URBMI and NCMS have a lower reimbursement rate for tuberculosis. The Zhenjiang City government has combined the NCMS and URBMI into URBMI. Under the free-TB service policy for tuberculosis, basic health insurance plays a small role in TB treatment [27]. Basic health insurance usually does not cover much of the outpatient service or provides a low reimbursement rate [28], which may drive TB patient hospitalization rates. The basic health insurance policy increased the OOP costs of TB and even resulted in CHE [29]. A study funded by GFATM revealed that only $41 \%$ of the counties covered the outpatient costs by basic health insurance, and the reimbursement rate was approximately $50 \%$. The amount of reimbursement was approximately $400 \mathrm{CNY}$ [30]. Another study in eastern China showed that the reimbursement rate covered by NCMS was only 25.1\% [31]. To some extent, the lower reimbursement rate leads to the higher admission rate. Some TB patients will accept hospitalization because of reimbursement [9]. Currently, in most places of China, basic health insurance partly reduced the economic burden on $\mathrm{TB}$, though patients still cannot bear OOP expenditures [32].

During the implementation of the Gates Foundation programme, Zhenjiang City increased the reimbursement 
rate for tuberculosis outpatients and inpatients to $80 \%$. However, this reimbursement rate was limited to the service package. Constraints of the service package, the inpatients in Zhenjiang City benefited approximately $70 \%$ reimbursement rate indeed. We observed that the average total cost in the service package was 7219.78 $\mathrm{CNY}$, and the ratio of OOP costs to total costs was $18.58 \%$, which achieved the goals of the programme. However, hospitals often provided TB patients with extra services and medicines beyond the service package, such as liver protection drugs, second-line anti-TB drugs, and extra non-recommended lab tests, which were not on the reimbursable list or on the list of free TB services. Therefore, inpatients still needed to pay large amounts of money for the costs out of the service package, and the ratio of OOP costs to total costs was above $40 \%$. Although the inpatients paid large amounts of money out of the service package, the median total cost was $11674.20 \mathrm{CNY}$, which was still lower than other studies in Jiangsu Province, which was 20411 CNY in Lianyungang City [33] and $15500 \mathrm{CNY}$ in Zhangjiagang City [6].

Results from generalized linear regression analysis showed that the average total costs of smear-positive patients (12384.00 CNY) was higher than that of smearnegative patients (11260.25 CNY). Sputum smear positivity often indicates that the patient's condition is relatively serious, which has a direct impact on hospitalization costs. In addition, positive sputum smears can affect the length of hospital stay indirectly and increase the total costs of hospitalization. Studies on hospitalization costs for tuberculosis patients have shown that the length of hospital stay has a direct impact on hospitalization costs [34]. Another analysis of hospitalization costs for inpatients with tuberculosis in a designated tuberculosis hospital in Tianjin City in China [35] indicated that the length of hospital stay was the greatest impact on TB patient hospitalization costs. The longer the patient stays in the hospital, the higher the cost.

We observed that occupation was one of the factors associated with total costs and OOP costs. The costs of manual labourers were higher than those of other groups. In our study, most manual labourers, including farmers, rural migrant workers and shepherds, were undereducated. Previous studies suggested that patients with lower education levels were associated with low incomes [36]. Due to an insufficient understanding of tuberculosis and poor incomes, these patients often delay seeking medical care. When they were diagnosed with tuberculosis, the symptoms were often stronger or accompanied by other complications, resulting in high costs of treatment [37]. In a systematic review, Sreeramareddy et al. [38] described the time delay in diagnosis of tuberculosis patients in China as approximately 25 to 714 days. A survey conducted by Dr.
Needham [39] in Zambia indicated that patients with a high education level could recognize the symptoms of tuberculosis and seek medical service in time. In addition, most of the manual labourers in our study were covered by URBMI (65.6\%), and the reimbursement rate out of the service package was lower than that of other groups, resulting in higher OOP costs than in other groups. The income of manual labourers should also be affected by the loss of work, the costs of diet, transportation, etc. during hospitalization, and the actual economic burden of these patients should be heavier. The OOP cost for students was lower than that of other groups. The reason is that the reimbursement rate of student insurance in many areas of China is higher than that of UEBMI and URBMI. The results of our study also revealed that age was associated with OOP costs. As the patients' age increased, the ALOS was shortened. The ALOS of the elderly over 60 years was the shortest $(23.28 \pm 16.19$ days $)$, which was 10 days less than that of the other groups, reducing the hospitalization expenses.

Despite some limitations, the key findings of our study can still reveal the issues that tuberculosis patients faced in Zhenjiang City. High out-of-pocket payments can lead to catastrophic health expenditure. Based on the findings, we would like to propose that health policy makers should take further steps to control the high TB patient hospitalization rates and inpatient service expenditure. First, revise the reimbursement policies relevant to $\mathrm{TB}$ treatment, expand the service package to include more medical items. Second, formulate TB treatment guideline and supervise its implementation to encourage the designated hospitals to provide necessary medical services and as a result reduce the financial burden on TB patients.

\section{Study limitations}

Some limitations existed in this study. First, we did not obtain all the expenditure records of the 211 inpatients and may not be able to overall reflect the economic burden of inpatients. Second, we only analysed the medical expenditures of inpatients; the expenditures of outpatients, including transportation, accommodation and food, and the loss of income due to the disease were not analysed because of the lack of data collected. High expenditure was associated with companions and transportation [40]. Third, Zhenjiang City has 3 counties, and the data were not obtained in this study. We planned to collect and analyse the data in further study.

\section{Conclusion}

We observed that the admission rate of TB patients in Zhenjiang City was $62.1 \%$. Within the service package, the reimbursement rates achieved $80 \%$, and the medical expenditures for TB were also maintained below 8000 
CNY per patient. However, massive expenditures out of the service package still existed. Despite advances in TB insurance policies, there are substantial costs associated with TB diagnosis and treatment, and TB patients still face a heavy financial burden. Health care providers may expand the items included in the service package, and revise the reimbursement policies relevant to TB treatment, to encourage the designated hospitals to provide appropriate medical services and to reduce the financial burden on TB patients.

\section{Additional files}

Additional file 1: Details of the 356 TB patients. These data contain demographic and social characteristics of the 356 TB patients, including gender, age, occupation, patient category, residence, sputum smear test, hospitalization status, type of health insurance, etc. (XLS $70 \mathrm{~kb}$ )

Additional file 2: Details of the 221 TB inpatients. These data contain the hospitalization records of 221 inpatients, including hospitalization times, length of hospital stay, and type of health insurance. (XLS $48 \mathrm{~kb}$ )

Additional file 3: Medical expenditure of the 141 inpatients. These data contain the social characteristics and hospitalization expenditures of 141 TB inpatients, including total costs and OOP costs. (XLS 44 kb)

\section{Abbreviations}

ALOS: Average length of stay; CDC: Centers for Disease Control and Prevention; CHE: Catastrophic health expenditure; CNY: Chinese Yuan; DOTS: Directly observed treatment short-course; GDP: The gross domestic product; HIS: Hospital Information System; HRS: Hospital Reimbursement System; NCMS: New Rural Cooperative Medical System; NTP: The National Tuberculosis Control Program; OOP: Out-of-pocket; TB: Tuberculosis; TMIS: China TB Management Information System; UEBMI: Urban Employee Basic Medical Insurance scheme; URBMI: Urban Resident Basic Medical Insurance scheme; WHO: World Health Organization

\section{Acknowledgements}

This study was partially supported by the programme entitled "China National Health and Family Planning Commission and the Gates Foundation TB Project" - a collaboration between the Government of China and the Bill and Melinda Gates Foundation. The authors would like to thank the Project Management Office for undertaking the survey and the data collection. The authors would also like to express their appreciation to all staff in Zhenjiang City for their participation in this study. The funders had no role in the study design, data collection, analysis, decision to publish, or preparation of the manuscript.

\section{Funding}

This work was supported by the Bill and Melinda Gates Foundation, Seattle, WA [grant number 51914] and the Health Research fund of the Jiangsu Provincial Commission of Health and Family Planning [grant number Z201505]. The funding bodies were not involved in the research process (design of the study, data collection, analysis or interpretation of data) or in writing of the manuscript.

\section{Availability of data and materials}

All data generated or analysed during this study are included in this published article and its supplementary information files.

\section{Authors' contributions}

$Y Z, L Z$ and $W L$ designed the study. YZ, HJ, HP and WL were involved with data collection. $Y Z, C C$ and $L Z$ analysed the data and prepared the tables. YZ wrote the first draft of the paper. YZ, CC, HJ, HP, LZ and WL edited and prepared the final version of the paper for journal submission. All authors have approved this version for publication.

\section{Ethics approval and consent to participate}

The study was conducted in accordance with the Declaration of Helsinki, and the protocol was approved by the Ethics Committee of the Chinese Centers for Disease Control and Prevention (Reference number not appropriate). This study used only routine data and did not involve any human participation; therefore, the application for waiving informed consent was accepted by the Ethics Committee.

\section{Consent for publication}

Not applicable.

\section{Competing interests}

The authors declare that they have no competing interests.

\section{Publisher's Note}

Springer Nature remains neutral with regard to jurisdictional claims in published maps and institutional affiliations.

\section{Author details}

'Department of Chronic Disease Control and Prevention, Centers for Disease Control and Prevention of Jiangsu Province, 172 Jiangsu Road, Nanjing 210009, Jiangsu Province, People's Republic of China. ${ }^{2}$ Centers for Disease Control and Prevention of Zhenjiang City, Zhenjiang, Jiangsu Province, People's Republic of China. ${ }^{3}$ No.3 Hospital of Zhenjiang City, Zhenjiang, Jiangsu Province, People's Republic of China.

Received: 28 February 2018 Accepted: 9 January 2019

Published online: 18 January 2019

\section{References}

1. WHO. Global tuberculosis report. 2018:2018. Available at: http://www.who. int/tb/publications/global_report/en/ Accessed October 15, 2018.

2. Potter $J$, Inamdar $\mathrm{L}$, Okereke $\mathrm{E}$, et al. Support of vulnerable patients throughout TB treatment in the UK. J Public Health (Oxf). 2016;38:391-5.

3. Su K, Wang LX, Tao T, et al. Analysis of the economic risk of disease and its influencing factors among pulmonary Tuberculosis patients in four mountainous counties in China. Chinese Health Econ. 2011;30(2):53-5.

4. Zurcher K, Ballif M, Zwahlen M, et al. Tuberculosis mortality and living conditions in Bern, Switzerland, 1856-1950. PLoS One. 2016;11:e0149195.

5. Nelson L, Wells CD. Global epidemiology of childhood tuberculosis. Int J Tuberc Lung Dis : the official journal of the International Union against Tuberculosis and Lung Disease. 2004;8:12.

6. Jiang W, Qiu SS, Lu H, et al. Factors affecting the economic burden of patients with pulmonary tuberculosis in Zhangjiagang county. Chin J Antituberc. 2014;36(2):98-103.

7. Wei X, Zou G, Yin J, et al. Comparing patient care seeking pathways in three models of hospital and TB programme collaboration in China. BMC Infect Dis. 2013;13:9

8. Tuberculosis NTSGOTESSF, Duanmu HJ. Report on fourth national epidemiological sampling survey of tuberculosis. Chin J Tuberc Respir Dis. 2002;25:3-7.

9. Li XX, Liu XQ, Jiang SW, et al. Survey on TB patients'health-seeking behaviors and their influence factors under TB control model of designated hospitals. Fudan Univ J Med Sci. 2013;40(6):718-23.

10. Chida N, Ansari $Z$, Hussain $H$, et al. Determinants of default from Tuberculosis treatment among patients with drug-susceptible Tuberculosis in Karachi, Pakistan: a mixed methods study. PLoS One. 2015;10:e0142384.

11. Li RZ, Ruan $Y Z$, Sun $Q$, et al. Effect of a comprehensive programme to provide universal access to care for sputum-smear-positive multidrugresistant tuberculosis in China: a before-and-after study. Lancet Glob Health. 2015;3:e217-28.

12. Xu WG, Lu W, Zhou Y, et al. Adherence to anti-tuberculosis treatment among pulmonary tuberculosis patients: a qualitative and quantitative study. BMC Health Serv Res. 2009;9:169.

13. Zhu MM, Wang J, Dib HH, et al. Enhancing the management of crossregional transfer of floating Tuberculosis cases by active follow-up and communication. Eur J Pub Health. 2011;22:577-82.

14. Wang LD, Liu JJ, Chin DP. Progress in tuberculosis control and the evolving public-health system in China. Lancet. 2007;369:691-6. 
15. WHO. Treatment of tuberculosis Guidelines for national programmes, 4th edition. 2010. Available at: https://www.who.int/tb/publications/ 9789241547833/en/. Accessed 16 Jan 2019.

16. Ronald LA, FitzGerald JM, Benedetti A, et al. Predictors of hospitalization of tuberculosis patients in Montreal, Canada: a retrospective cohort study. BMC Infect Dis. 2016;16:679.

17. Sleigh AC. Health-system reforms to control tuberculosis in China. Lancet. 2007;369:2.

18. Du YX, Xie H, Tian D, et al. Costs and effects incurred during quarantined inpatient treatment of smear and culture positive pulmonary tuberculosis[]]. Chin J Antituberc. 2016;38(11):1000-3.

19. Lv CF, Sun $Q, L i R Z$, et al. Analysis on the hospitalization expense of multidrug resistant tuberculosis patients treated in standard package[]]. Chinese J Health Policy. 2013;6(4):66-70.

20. Chen $\mathrm{M}$, Song $\mathrm{H}$, Wang JL, et al. Analysis of tuberculosis patients' hospitalization expenses of a middle first-class hospital in Jiangsu province[]]. Modern Prev Med. 2017:44(2):275-7.

21. Wu TY, Liu FY. Current situation of tuberculosis control in designated hospitals in China[J]. Chin J Antituberc. 2014;36(4):290-3.

22. Russell S. The economic burden of illness for households in developing countries: a review of studies focusing on malaria, tuberculosis, and human immunodeficiency virus/acquired immunodeficiency syndrome. Am J Trop Med Hyg. 2004;71:147-55.

23. Pan $\mathrm{HQ}$, Bele $\mathrm{S}$, Feng $\mathrm{Y}$, et al. Analysis of the economic burden of diagnosis and treatment of tuberculosis patients in rural China. Int J Tuber Lung Dis: the official journal of the International Union against Tuberculosis and Lung Disease. 2013;17:6

24. Cheng G, Zhou GL, Li RZ, et al. Analysis of medical cost of tuberculosis patients in rural Shandong province. Chinese Rural Health Serv Adm. 2004;24(4):21-3.

25. Wang LH, Wang XW. Basic characteristics and cost analysis for 2975 discharged patients with Tuberculosis. Today Nurse. 2007;14(10):4-7.

26. Wang $N$, Wang $L X$, Li RZ. The analysis of medical expense and economic burden in new smear positive pulmonary tuberculosis cases from 4 prefecture level designated TB hospitals. Chin J Antituberc. 2012;34(2):79-84.

27. Zhang CY, Wang LX, Cheng J, et al. Analysis on the national reimbursement situation of outpatient medical expenses of pulmonary tuberculosis in different medical insurance systems in 2009. Chin J Antituberc. 2012;34(9): $576-9$.

28. Wei XL, Zou GY, Yin J, et al. Effective reimbursement rates of the rural health insurance among uncomplicated tuberculosis patients in China. Trop Med Int Health : TM \& IH. 2015;20:304-11.

29. Ruan YZ, He GX, Zhang H, et al. Analysis of the socio-economic status of 1301 tuberculosis cases. Chin J Antituberc. 2012;34(9):572-5.

30. Jiang $S W$, Zhang $H$, Liu XQ, et al. The development and outlook of tuberculosis designated hospital[J]. Chin J Antituberc. 2013;35(10):765-7.

31. Chen $B$, Wang $X$, Zhong JM, et al. Reimbursement of new rural CMS to rural TB patients in Zhejiang province[]]. Chinese Rural Health Serv Adm. 2011; 31(6):407-9

32. Chen ZP, Yang J, Chen HJ. Analysis on the reimbursement of tuberculosis in Guizhou Province[J]. Guizhou Med J. 2012;36(1):56-7.

33. Wang $Q$, Wang LX, Li RZ, et al. Analysis of the medical expenses and economic burden of pulmonary tuberculosis patients in three cities[]]. Chin J Antituberc. 2013;35(4):240-5.

34. Wang YF, Xu LZ, Zhou CC, et al. Path analysis on determinants of Tuberculosis inpatient cost in ShanDong Province[J]. Chinese J Health Stat. 2009;26(1):26-8.

35. Xie W, Ma LY, Ma PA, et al. Path analysis on hospitalization cost factors of tuberculosis patients []]. Chinese J Prev Control of Chronic Dis. 2015;23(7):559-60

36. Du SC, Xu CH, Wang $L$, et al. Investigation and analysis on the medical expenses and economic burden of pulmonary tuberculosis patients in five counties in Xinjiang[J]. Chin J Antituberc. 2018:40(6):609-15.

37. Wang J, Yin SD, Zhang WW. Analysis on the economic burden and influence factors of tuberculosis patients[J]. Pract Prev Med. 2015;22(11):1352-4.

38. Sreeramareddy $C T$, Panduru KV, Menten J, et al. Time delays in diagnosis of pulmonary tuberculosis: a systematic review of literature[]]. BMC Infect Dis. 2009;9(91):10.

39. Needham DM, Foster SD, Tomlinson G, et al. Socio-economic, gender and health services factors affecting diagnostic delay for tuberculosis patients in urban Zambia[J]. Tropical Med Int Health. 2001;6(4):256-9.

40. de Cuevas RM, Lawson L, Al-Sonboli N, et al. Patients direct costs to undergo TB diagnosis[]]. Infect Dis Poverty. 2016;5:24.

Ready to submit your research? Choose BMC and benefit from:

- fast, convenient online submission

- thorough peer review by experienced researchers in your field

- rapid publication on acceptance

- support for research data, including large and complex data types

- gold Open Access which fosters wider collaboration and increased citations

- maximum visibility for your research: over $100 \mathrm{M}$ website views per year

At BMC, research is always in progress.

Learn more biomedcentral.com/submissions 